13;15

\title{
Твердотельная хаотическая автоколебательная система микроволнового диапазона упрощенной структуры
}

\author{
() Н.А. Максимов, А.И. Панас
}

Институт радиотехники и электроники им. В.А. Котельникова РАН (Фрязинский филлиал), Фрязино, Московская область E-mail: maksna49@mail.ru

Поступило в Редакцию 17 июля 2016 г.

Предложена, реализована и исследована твердотельная автоколебательная система, позволяющая получать сверхширокополосные хаотические сигналы в микроволновом диапазоне. Система имеет простую структуру, состоящую из активного элемента (биполярный транзистор) и единственного реактивного элемента (индуктивность). Проведено экспериментальное исследование бифуркационных явлений и типовых колебательных режимов системы. Проанализированы энергоэффективность системы и возможность ее реализации в виде чипструктуры.

DOI: $10.21883 /$ PJTF.2017.03.44232.16429

Радиотехнические и электронные автоколебательные системы с хаотическим поведением внесли во многом определяющий вклад в изучение динамического хаоса. Являясь объектом исследований, они позволяли проводить натурные эксперименты, подтверждая выводы теории, а подчас давали богатую пищу для новых изысканий. Структура и конструкции систем отличались большим разнообразием. Они были реализованы как в вакуумном, так и в твердотельном исполнении $[1,2]$. При этом простота структуры не являлась определяющим фактором, но была положительным моментом, так как позволяла адекватно описывать динамику систем с помощью несложных математических моделей. Со временем ситуация стала меняться. Хаотические колебания (сигналы) становятся востребованными в различных приложениях [3-5], что делает актуальным разработку и создание источников (генераторов) 


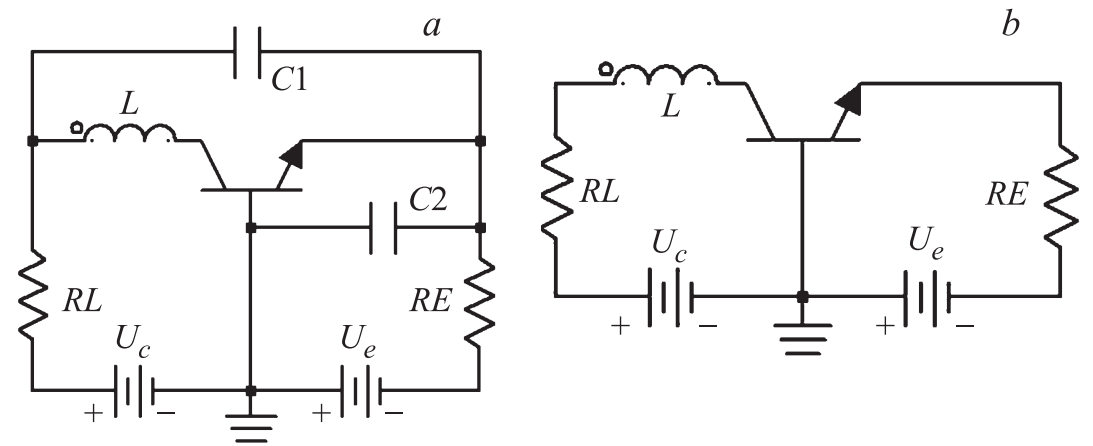

Рис. 1. Схема генератора Колпитца: $a-$ классическая, $b-$ с упрощенной структурой.

таких сигналов. Каждое из конкретных приложений предъявляет к источникам определенные требования, связанные с обеспечением набора потребительских свойств, одними из которых являются простота конструкции, рабочие диапазоны и полосы частот генерируемых сигналов, энергоэффективность генераторов и т.п. В работе предлагается твердотельный вариант источника сверхширокополосных хаотических колебаний микроволнового диапазона, отличительной особенностью которого является исключительная простота конструкции при достаточно высокой энергоэффективности генерации.

Одной из простейших по структуре твердотельных хаотических автоколебательных систем является генератор Колпитца [6], представляющий собой классическую схему емкостной трехточки. Один из вариантов схемы генератора приведен на рис. $1, a$.

Со временем, на этапе поиска приложений динамического хаоса пришло понимание, что потенциальные области применения хаотических сигналов связаны с более высокочастотными диапазонами. Это стимулировало исследователей на разработку источников хаотических сигналов в указанных диапазонах. Данная тенденция не обошла и трехточечные автоколебательные схемы. Были предложены варианты таких схем с рабочей частотой в MHz-диапазоне [7], а впоследствии и в микроволновом диапазоне $[8,9]$. Несмотря на ряд специфических технических и технологических проблем, связанных с микроволновым

Письма в ЖТФ, 2017, том 43, вып. 3 
диапазоном, предложенные генераторы хаоса демонстрируют динамику, очень близкую к классической схеме. Так, на рис. 2, a приведены спектры мощности выходного сигнала генератора Колпитца, в котором в качестве активного элемента использовался $n-p-n$-биполярный SiGe транзистор BFP 620F с граничной частотой $65 \mathrm{GHz}$. Параметры пассивных элементов схемы (рис. 1,a) соответствовали следующим значениям: $C 1=C 2=1 \mathrm{pF}, L=1 \mathrm{nH}, R L=33 \Omega, R E=390 \Omega$. Увеличение напряжения $U_{c}$ при фиксированном $U_{e}$ приводит сначала к возбуждению колебаний на частоте, близкой к $2.8 \mathrm{GHz}$, на смену которым через две бифуркации удвоения периода приходят хаотические колебания с центральной частотой около $4 \mathrm{GHz}$ и полосой частот от 2 до $6 \mathrm{GHz}$ по уровню $\sim 10 \mathrm{~dB}$. Как и в классической схеме, частотноизбирательная цепь рассматриваемого генератора формируется реактивными элементами $C 1, C 2$ и $L$, образуя $R L C$-фильтр нижних частот, a распределение мощности сигнала по диапазону частот и верхняя граница спектральной характеристики колебаний, возникающих в такой системе, определяются амплитудно-частотной характеристикой этого фильтра [2,9].

Как отмечено выше, функцию управляющих параметров исследуемой автоколебательной системы выполняют напряжения $U_{c}$ и $U_{e}$. Экспериментальное исследование режимов системы в зависимости от указанных параметров показало, что при низких напряжениях коллекторбаза $\left(U_{c} \sim 0-2 \mathrm{~V}\right)$ и высоких напряжениях эмиттер-база $\left(U_{e} \sim 6 \mathrm{~V}\right)$ в системе довольно легко возникают многочастотные колебания, однако переход к хаосу затруднителен, а возникающие хаотические колебания неустойчивы и существуют в узких зонах изменения питающих напряжений транзистора. Другие колебательные режимы системы наблюдались при высоком напряжении $U_{c} \sim 12 \mathrm{~V}$ и небольших $U_{e} \sim 0.75-1.5 \mathrm{~V}$. В этом случае хаотические колебания в системе возникали практически сразу при открывании перехода эмиттер-база и были устойчивы при изменении напряжения на переходе в указанных пределах (рис. 2,a).

Оценка энергетических характеристик генератора показывает, что при затраченной мощности $\sim 100 \mathrm{~mW}$, мощность его выходного сигнала (коллекторная цепь) составляет $\sim 2 \mathrm{~mW}$, что соответствует кпд $\sim 2 \%$.

В диапазоне сверхвысоких частот величины внешних емкостей и индуктивности, необходимые для генерации хаотических колебаний в исследуемой автоколебательной системе, измеряются единицами $\mathrm{pF}$ и $\mathrm{nH}$. Это, в свою очередь, означает, что они становятся соизмеримыми 

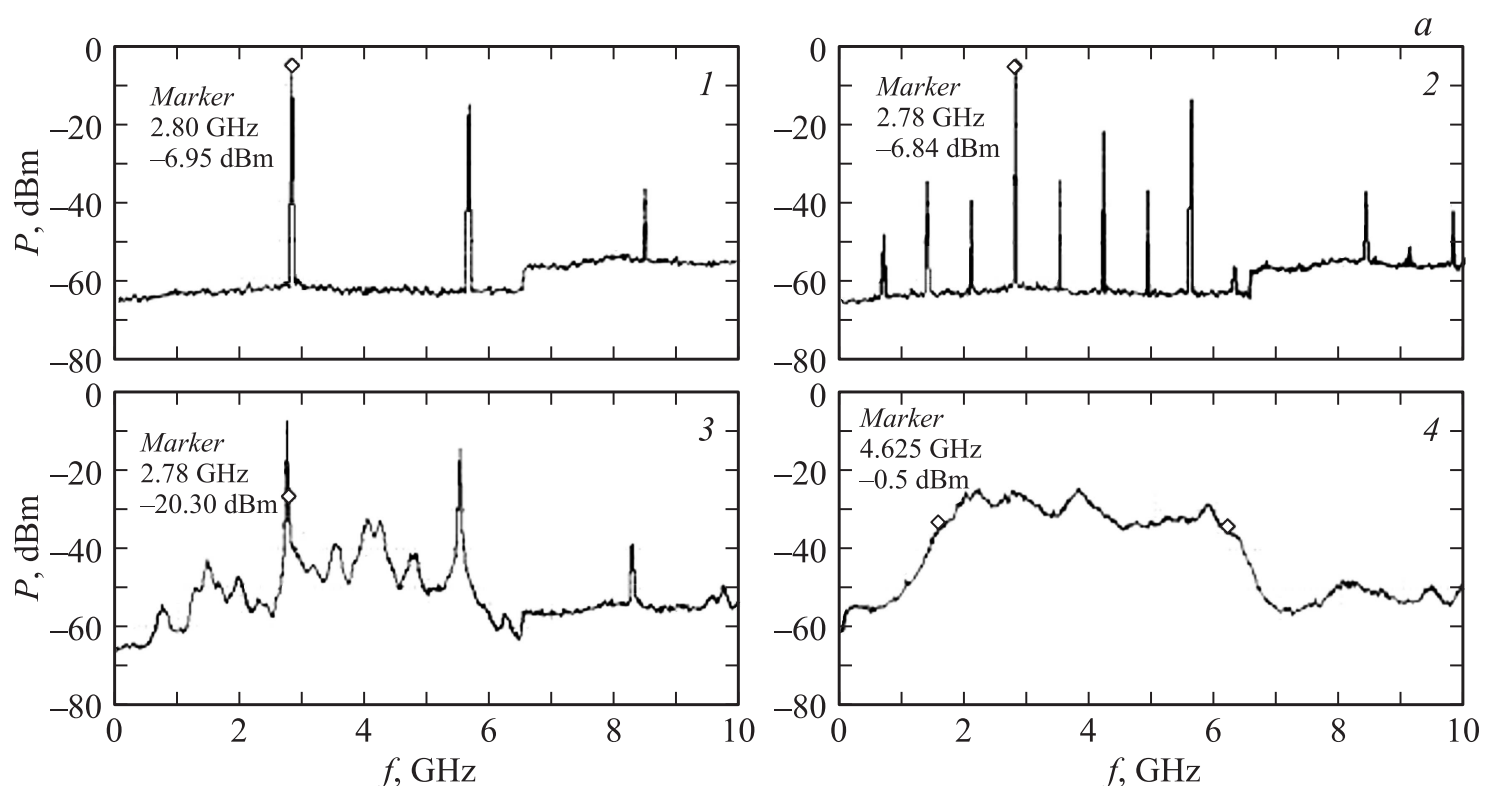

Рис. 2. Спектры мощности выходного сигнала генератора (коллекторная цепь) для типовых режимов генератора при увеличении напряжения $U_{c}(1-4)$ и фиксированном $U_{e}: a-$ классического генератора Колпитца, $b$-генератора с упрощенной структурой. 

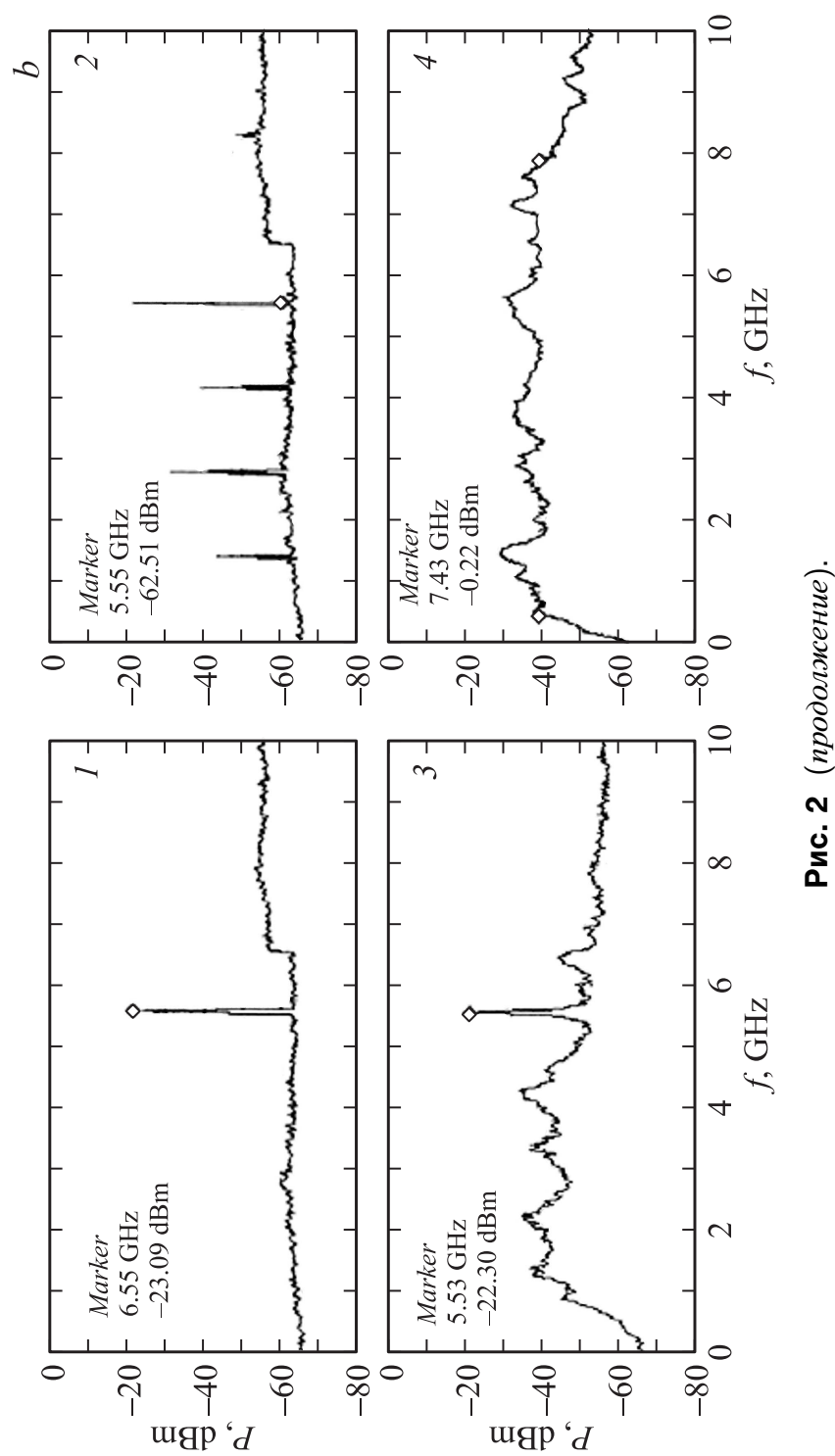

Письма в ЖТФ, 2017, том 43, вып. 3 
с емкостями $p-n$-переходов и паразитными индуктивностями используемых в системе СВЧ-транзисторов, которые начинают оказывать влияние на колебательные режимы. Влияние межэлектродных емкостей приводит к тому, что генерация колебаний в схеме может происходить и при отсутствии внешних емкостей $C 1, C 2$ (рис. $1, a)$. Обратная связь в этом случае осуществляется за счет внутренних емкостей $p-n$ переходов транзистора. Так, для кремний-германиевого транзистора BFP 620F емкость коллектор-эмиттер составляет $C_{c e} \sim 0.2 \mathrm{pF}$, а емкости других переходов соответственно $C_{k b}=0.12 \mathrm{pF}, C_{e b}=0.45 \mathrm{pF}$. При исключении внешних емкостей $C 1$ и $C 2$ в схеме генератора остается только один внешний реактивный элемент - индуктивность, который в совокупности с емкостями $p-n$-переходов транзистора и формирует в данном случае частотно-избирательную цепь генератора (рис. $1, b$ ).

Типичная картина развития колебаний в системе приведена на рис. $2, b$. При $L=1 \mathrm{nH}$ напряжение питания эмиттер-база было фиксированным и составляло $U_{e}=0.75 \mathrm{~V}$, а роль управляющего параметра выполняло напряжение коллектор-база, изменяемое в пределах $U_{c}=0-12 \mathrm{~V}$. Вплоть до $U_{c}=9 \mathrm{~V}$ в системе существовало колебание на частоте $\sim 5.6 \mathrm{GHz}$. Дальнейшее увеличение напряжения $U_{c}$ приводило к последовательному развитию субгармонических колебаний удвоенного периода и при достижении значений $11-12 \mathrm{~V}$ развивались устойчивые хаотические колебания. Важно отметить, что, несмотря на существенное упрощение структуры генератора, типовые режимы колебаний и сценарий их перехода от одного режима к другому хорошо соответствуют случаю классического генератора Колпитца (рис. 1,a). С другой стороны, с увеличением частоты генерации происходит расширение спектра мощности хаотических колебаний, полоса частот которых достигает $8 \mathrm{GHz}$. При этом мощность выходного сигнала (коллекторная цепь) составляла $2.5 \mathrm{~mW}$ при потребляемом токе $3 \mathrm{~mA}$ и суммарном напряжении питания $11.5 \mathrm{~V}$, что соответствовало кпд устройства $\sim 7 \%$.

Проведенное исследование показало, что в микроволновом диапазоне возможно создание сверхширокополосных твердотельных генераторов хаоса упрощенной структуры. В схеме емкостной трехточки (генератор Колпитца) можно использовать только один реактивный внешний элемент-индуктивность, что позволяет увеличить энергоэффективность системы и расширить полосу генерации. В модифицированной таким образом системе экспериментально зафиксированы устой-

Письма в ЖТФ, 2017, том 43, вып. 3 
чивые хаотические колебания в полосе частот $\Delta f=7.5 \mathrm{GHz}$ по уровню неравномерности спектральной характеристики $10 \mathrm{dBm}$ (рис. $2, b, 4)$.

С учетом современного интереса к использованию хаотических сигналов именно в СВЧ-диапазоне результаты работы могут оказаться полезными при разработке сверхширокополосных СВЧ-генераторов хаоса в чип-исполнении на основе SiGe-технологии.

\section{Список литературы}

[1] Кислов В.Я. // Радиотехника и электроника. 1980. Т. 25. № 8. С. 1683.

[2] Дмитриев А.С., Ефремова Е.В., Максимов Н.А., Панас А.И. Генерация хаоса. М.: Техносфера, 2012. $423 \mathrm{c}$.

[3] Дмитриев А.С., ЕФремова Е.В., Герасимов М.Ю. // Радиотехника и электроника. 2015. Т. 60. № 4. С. 1-9.

[4] Максимов Н.А., Панас А.И. // Электронная техника. Сер. СВЧ-техника. 2014. B. 2 (521). C. 5-13.

[5] Panas A.I., Maksimov N.A. // Euras. Phys. Techn. J. 2015. V. 12. N 2 (24). P. 4-9.

[6] Kennedy M.P. // IEEE Transactions on Circuits and Systems. 1: Theory and Applications. 1994. V. 41. N 11. P. 771-774.

[7] Tamasevicius A., Bumeliene S., Lindberg E. // Electron. Lett. 2004. V. 40. P. $1569-1570$.

[8] Li J.X., Wang Y.C., Ma F.C. // Nonlinear Dyn. 2013. V. 72. P. 575-580.

[9] Максимов Н.А., Панас А.И. // Труды 2 Российско-Белорусской науч.-техн. конференции ,Элементная база отечественной радиоэлектроники: импортозамещение и применение“. Нижний Новгород, Россия. 2015. 